\title{
Avaliação de extratos de quebra- pedra (Phyllanthus sp) frente à patógenos causadores de infecções no trato urinário
}

DOMINGUES K.; GONÇALVES A.; OLIVEIRA C.P.'; PERIM C.M.'; GONÇALVES F.B. ${ }^{2 *}$

Universidade Paulista, UNIP, Avenida Independência, 210 - Éden, Sorocaba - SP, 18087-10, Sorocaba, SP, Brasil. 2Universidade Paulista, UNIP, São Paulo, SP,Brasil - Rua Dr. Bacelar, 1212 - Vila Clementino - São Paulo - SP CEP 04026-002. *Autor para correspondência: flavioburatti@hotmail.com

\begin{abstract}
RESUMO: O trato urinário normalmente é estéril, no entanto, pode ser contaminado por agentes etiológicos provenientes da microbiota intestinal, dentre os mais comuns pode-se destacar a Escherichia coli. Os microrganismos estão se tornando cada vez mais resistentes a múltiplos antimicrobianos. É notória, portanto, a necessidade de encontrar novas substâncias com propriedades antimicrobianas. Portanto, foram avaliados diferentes extratos de Phyllanthus sp, frente a microrganismos causadores de infecções no trato urinário e comparadas as técnicas de hole-plate e disco difusão. Para ambas as técnicas avaliadas, o extrato de 72 horas mostrou melhor atividade antimicrobiana, na técnica de disco difusão, a bactéria mais sensível foi o Staphylococcus saprophyticcus, que apresentou CMI (Concentração Mínima Inibitória) de $15,84 \mathrm{mg} / \mathrm{mL}$. Com a utilização da técnica de hole-plate, a bactéria mais sensível observada foi Staphylococcus aureus, com valor de CMI igual ao reportado anteriormente. Foi observado que os extratos alcoólicos obtiveram maior eficiência em relação às infusões, que a técnica de hole-plate revelou ser mais eficiente que a técnica de disco difusão e que os cocos Gram positivos foram mais susceptíveis quando comparadas aos bacilos Gram negativos e fungos.
\end{abstract}

Palavras-chave: Phyllanthus sp, infecção do trato urinário, patógenos.

\begin{abstract}
Evaluation of Phyllanthus sp extracts in face of Pathogen Causers of Urinary Treat Infections. Commonly, the urinary treat is sterile, but it can also be contaminated by etiological agents from the intestinal treat, of which the Escherichiacoli is the most common one. These microorganisms are increasingly becoming more resistant to multiple antibiotics. It became necessary to find new substances with antimicrobial properties, so the purpose of this paper is to evaluate different Phyllanthus sp extracts- in face of microorganisms which cause the urinary treat infections- and compare it to the hole-plate and disk diffusion techniques. The 72 hours extraction showed better antimicrobial activity in both methods. Using disk diffusion, the most sensitive bacterium was the Staphylococcus saprophyticcus, with the MIC of $15,84 \mathrm{mg} / \mathrm{mL}$. While using the technique of hole-plate, the most sensitive bacterium was the Staphylococcus aureus, with the same MIC of the previous cited bacterium. This study showed that the alcoholic extracts were more efficient than the infusions. It can also be observed that the hole-plate technique seems to be more efficient than the disk diffusion one, and the Gram positive cocci bacteria were more sensitive than the Gram negative bacilli and fungi.
\end{abstract}

Keywords: Phyllanthus sp, urinary treat infection, pathogen.

\section{INTRODUÇÃO}

O trato urinário é considerado estéril acima da uretra, mas normalmente colonizado com muitos tipos diferentes de bactérias (Horner et al., 2006). Os agentes etiológicos de infecção do trato urinário são, geralmente, provenientes da microbiota intestinal (Almeida et al., 2007). Os maiores responsáveis pela infecção do trato urinário são as bactérias gram- negativas entéricas, especialmente Escherichia coli, seguido dos demais gram-negativos como Klebsiella $\mathrm{sp}$, Enterobacter sp, Acinetobacter sp, Proteus sp (Heiilberg \& Schor, 2003), Serratia sp e leveduras. Particularmente espécies de Cândida e bactérias não fermentadoras, como Pseudomonas aeruginosa, são organismos mais frequentemente encontrados 
em infecções adquiridas em hospitais, uma vez que a resistência destes microrganismos aos antibióticos favorece sua seleção para contaminação dos pacientes hospitalizados (Schaechter et al., 2002; Koneman et al., 2001). A infecção por fungo normalmente acomete pacientes imunossuprimidos como: transplantados e portadores da Síndrome da Imunodeficiência Adquirida (Vieira Neto, 2003).

As bactérias resistentes a múltiplos antimicrobianos representam um desafio no tratamento de infecções, é necessário, portanto, encontrar novas substâncias com propriedades antimicrobianas para serem utilizadas no combate de diferentes microrganismos (Pereira et al., 2004). Em um estudo realizado por Lucchetti et al. (2005), hgbanalisando o perfil de sensibilidade dos principais agentes antimicrobianos, observouse baixa sensibilidade aos antibióticos de escolha primária, de fácil administração (medicamentos orais) e baixo custo, como a norfloxacina e o ciprofloxacina. Antimicrobianos como a gentamicina apresentaram baixa cobertura para os bacilos gramnegativos, sendo maior para $E$. coli, com $86,84 \%$ de sensibilidade, para as não fermentadoras da glicose, a sensibilidade variou de $55,47 \%$ a $63,15 \%$.

O aumento da resistência dos microrganismos, devido ao uso indiscriminado de antimicrobianos comerciais incentiva a busca de novas substâncias antimicrobianas a partir de várias fontes, incluindo de plantas (Komuraiah et al., 2009). Muitas plantas encontradas na flora brasileira são usadas na medicina natural, no tratamento de doenças tropicais, incluindo infecções bacterianas (Pereira et al., 2004), tais como as infecções do trato urinário. Por outro lado, as plantas produzem substâncias químicas, que podem atuar beneficamente sobre outros microrganismos ou agirem de forma tóxica. Portanto, para que o homem possa fazer uso medicinal de uma espécie, com segurança, é necessário que a mesma seja estudada sob ponto de vista químico, farmacológico e toxicológico (Ritter et al., 2002).

A quebra-pedra é uma planta que ocorre amplamente nas regiões tropicais, desenvolve-se em qualquer tipo de solo e pode ser encontrada em todo o território brasileiro (Nascimento et al., 2005). O gênero Phyllanthus compreende mais de 550 espécies, das quais grande número cresce no Brasil. São conhecidas popularmente por quebrapedra ou erva-pombinha (Garcia et al., 2004). Ocorre semelhança entre as espécies de Phyllanthus, entre elas, $P$. niruri L. e $P$. tenellus Roxb., característica que dificulta a identificação. A semelhança explica em parte o uso de ambas espécies supracitadas na medicina popular para os mesmos fins (Garcia et al., 2004).

Quebra-pedra é utilizada frequentemente para problemas renais e de bexiga (Aita et al., 2009). Internamente as folhas são usadas como diuréticas, litolíticas, eupépticas, em afecções do fígado, icterícia, cólicas renais, moléstias da bexiga, retenção urinária e como auxiliar na eliminação de ácido úrico. As raízes também são utilizadas em afecções hepáticas, e os frutos, as sementes e folhas para o controle do diabetes (Aita et al., 2009).

Os extratos de Phyllanthus têm compostos secundários como alcalóides, flavonóides, fenóis de lignina, tanino e terpeno. Muitos dos constituintes ativos são atribuídos biologicamente à lignina, glicosídeos, flavonóides e propanol de fenila que são encontrados nas folhas, caule e raízes da planta (Komuraiah et al., 2009).

Os constituintes químicos presentes na espécie já estão bem estabelecidos, notadamente os taninos (Castro-Chaves et al., 2002), os flavonóides (quercetina I, astragalina, quercitrina e rutina $X X I$ ), lignanas (filantina e hipofilantina), triterpenóides, alcalóides (filocrisina, filalvina) e um alcalóidepirrolizidínico; cineol, cimol, linalol, salicilato de metila, securimina, filantiolina, ácido salicílico (Aita et al., 2009). Foram isolados compostos fenólicos das raízes com ácido gálico, (-)-epicatequina, (+)-galocatequina, (-)-epigalocatequina, (-)-epicatequina-3-O-galate e (-)-epigalocatequina- 3-O-galate. Das folhas e caule taninos hidrolisáveis como geranina, corilagina e galoilglicose (Aita et al., 2009).

Esta espécie foi também uma das mais estudadas pelo Programa de Plantas Medicinais da CEMNE- Central de Medicamentos, que realizou financiamento de várias pesquisas as quais geraram dados demonstrativos da segurança e eficácia dessa espécie. Concluindo que $P$. niruri é desprovida de efeito tóxico agudo. Surpreendentemente também foi observado que esta espécie possui efeito uricosúrico e elevada filtração glomerular, o que sugere utilização potencial não só como efeito lítico e ou preventivo na formação de cálculos urinários, mas também possível utilização em pacientes hiperuricêmicos e pacientes com insuficiência renal - Parecer Técnico nº 043/85 (Brasil, 2006).

As propriedades antimicrobianas de substâncias presentes em extratos e óleos essenciais produzidos pelas plantas como uma consequência do metabolismo secundário, também são reconhecidas empiricamente há séculos, no entanto requerendo comprovações científicas (Jansen, 1987).

No Brasil, a investigação sobre produtos naturais com atividade antimicrobiana também aumentou significativamente nos últimos anos. Entretanto, apesar da rica biodiversidade, somente estão disponíveis dados sobre 44 espécies de plantas pertencentes a 20 famílias, com atividade

Rev. Bras. PI. Med., Campinas, v.17, n.3, p.427-435, 2015. 
positiva, incluindo espécies nativas e exóticas (Duarte, 2006). O baixo número de registros pode ser consequência da disseminação restrita dos resultados de pesquisa, geralmente apresentados em eventos científicos locais ou regionais. Além disso, a maioria dos estudos são testes isolados com uma ou poucas espécies, geralmente baseados em informações etnofarmacológicas, diferentemente de pesquisas que abrangem a flora de uma região definida, onde várias famílias botânicas são estudadas (Duarte, 2006).

Tendo em vista esses princípios e a necessidade de um maior entendimento acerca das propriedades antimicrobianas do extrato de Phyllanthus sp, objetivou-se neste estudo avaliar a susceptibilidade de cepas de E. coli, P. vulgaris, $S$. aureus, S. saprophyticcus e C. albicans frente a diferentes extratos de Phyllanthus sp, e comparar a eficiência de diferentes métodos de extração dos princípios ativos.

\section{MATERIAIS E MÉTODOS}

A capacidade dos extratos em inibir o crescimento de microrganismos foi avaliada a partir de duas metodologias distintas, e posteriormente comparadas em relação à sua eficácia e sensibilidade. Os materiais: o preparado em pó (100 gramas) e a granel (1.500 gramas) de Phyllanthus sp. foram adquiridos respectivamente em farmácia de manipulação e em lojas de produtos naturais.

\section{Preparo dos extratos Infusão com o Pó}

Foram Misturados 72,61 gramas de pó de extrato de Phyllanthus sp, em $350 \mathrm{~mL}$ de água destilada em temperatura de ebulição $\left(100^{\circ} \mathrm{C}\right)$ e deixado em repouso a temperatura ambiente sem luminosidade por aproximadamente 3 horas. Decorrido o tempo a amostra foi filtrada e armazenada em frasco âmbar e ao abrigo da luz.

\section{Extrato Alcoólico de $\mathbf{4 8}$ horas e $\mathbf{7 2}$ horas}

Foram utilizados 1.000 gramas de Phyllanthus sp, a granel, fracionada em duas partes, de 500 gramas da planta para $1.500 \mathrm{~mL}$ de álcool absoluto (99,8\%). A primeira parte foi deixada em repouso por 48 horas, e a outra por 72 horas. Transcorrido o tempo, as amostras foram filtradas e os extratos evaporados, com auxílio de evaporador rotativo (Quimis Aparelhos Científicos LTDA), a uma temperatura de $70^{\circ} \mathrm{C}$ e liofilizadas. Para o uso, os extratos foram resuspendidos em $10 \mathrm{~mL}$ de água destilada.

\section{Extrato Hidroalcoólico \\ Para a obtenção do extrato, foram utilizadas}

250 gramas da planta, a granel, em $750 \mathrm{~mL}$ da solução hidroalcoólica a $40 \%$ e deixada em repouso por 24 horas. Decorrido o tempo, a amostra foi filtrada e conservada em frasco âmbar ao abrigo da luz. O álcool a $40 \%$ testado previa e isoladamente não se mostrou suficientemente capaz de promover uma ação bactericida ou bacteriostática, neste caso sua utilização se dá unicamente com fim a extração dos princípios ativos contidos no extrato vegetal, sem a necessidade de evaporação posterior.

\section{Infusão}

Para confecção desse extrato, foram adicionados 250 gramas da planta, a granel, em $1.500 \mathrm{~mL}$ de água destilada em temperatura de ebulição $\left(100^{\circ} \mathrm{C}\right)$ e deixado em repouso, a temperatura ambiente ao abrigo de luz, por aproximadamente 5 horas, depois de transcorrido este período a amostra foi filtrada e armazenada em frasco âmbar.

\section{Avaliação de sensibilidade \\ Técnica de Hole - Plate}

Para esta metodologia, as suspensões dos microrganismos a serem testadas foram preparadas de acordo com a escala 0,5 de Mac Farland (Cefar), e foram semeadas por tapete, com o auxílio de um swab estéril, na superfície do Ágar Mueller Hinton (Difco, interlab). Em seguida, as cavidades (holeplate) com diâmetro de $6 \mathrm{~mm}$ foram confeccionadas com auxílio de pipeta Pasteur plástica estéril (Fernandes et al., 2005; Packer \& Luz, 2007). Em cada poço foi adicionado $40 \mu \mathrm{L}$ dos extratos em diferentes diluições $(1: 5,1: 10,1: 20,1: 40,1: 80$, $1: 160,1: 320$ e 1:640). As placas foram incubadas a $37^{\circ} \mathrm{C}$ por $18-24$ horas, após esse período, os halos de inibição foram medidos e os resultados expressos em milímetros e pela Concentração Mínima Inibitória (CMI).

\section{Técnica de Disco Difusão}

De acordo com a escala 0,5 de Mac Farland os microrganismos foram semeados, por tapete, nas placas com uso do ágar Mueller Hinton como substrato. Cada diluição do extrato impregnou discos de papel de filtro estéreis, dispostos na superfície do ágar previamente inoculado, conforme metodologia recomendada pela National Commitee for Clinical Laboratory Standards (NCCLS). Cada disco foi impregnado com $10 \mu \mathrm{L}$ dos extratos nas diferentes diluições $(1: 5,1: 10,1: 20,1: 40,1: 80$, $1: 160,1: 320$ e 1:640). Após incubação por 18-24 horas a $37^{\circ} \mathrm{C}$, os diâmetros das zonas de inibição ao redor do disco com extrato foram avaliados, bem como a Concentração Mínima Inibitória (CMI)

\section{Microrganismos utilizados nos teste de}




\section{atividade antimicrobiana}

Foram utilizados como microrganismos as cepas ATCC de E. coli (ATCC 25922), P. vulgaris (ATCC 13315), S. aureus (ATCC 25923), S. saprophyticcus (adquirida de isolado clínico) e da levedura C. Albicans (ATCC 10231), obtidas do setor de culturas microbianas do Instituto Adolfo Lutz de São Paulo (IAL-SP)

\section{RESULTADOS}

A E. coli foi inibida pela ação do extrato hidroalcoólico a $40 \%$ na análise das técnicas de hole-plate e disco difusão, e o $P$. vulgaris para o extrato hidroalcoólico $40 \%$, na técnica de disco difusão, e para o extrato alcoólico de 72 horas, na técnica de hole-plate. O S. aureus foi inibido em seu crescimento frente aos extratos hidroalcoólicos $40 \%$ e alcoólico nos tempos de repouso de 48 e 72 horas, nas duas técnicas analisadas. O S. saprophyticcus foi inibido em ambas as técnicas, para os extratos alcoólicos em repouso de 48 e 72 horas. E a C. albicans mostrou-se sensível somente para o extrato alcoólico em repouso de 72 horas e somente para a técnica de hole-plate. Todos os microrganismos proliferaram-se sem sofrer inibição nos testes com as infusões, tanto do produto a granel, quanto do pó. Para a técnica de disco difusão, a partir do extrato de 48 horas, as bactérias mais inibidas foram as do grupo Staphylococcus atingindo valor de CMI em torno de $6,67 \mathrm{mg} / \mathrm{mL}$ (Figura 1, Tabela 1) com halos, medidos com tamanho entre 8 e $13,5 \mathrm{~mm}$, nas diferentes diluições. No extrato de 72 horas, 0 S. saprophyticcus apresentou maior resposta, com

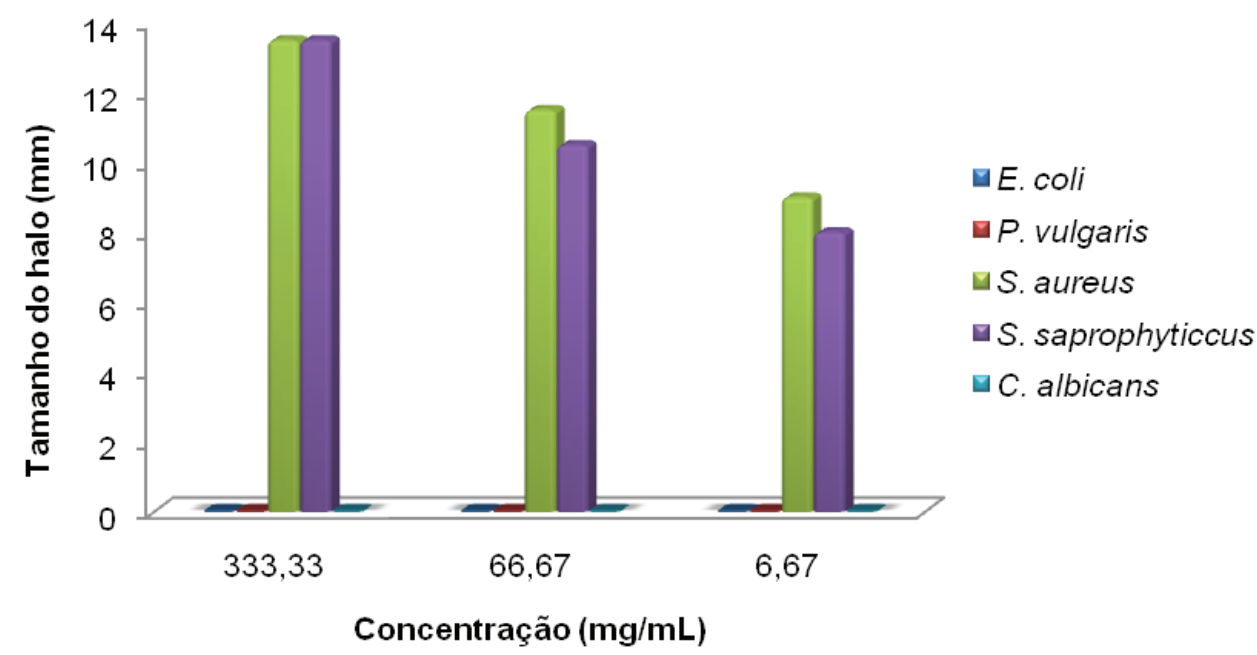

FIGURA 1. Resposta dos microrganismos frente ao extrato alcoólico (48 horas) - Análise por técnica de disco difusão

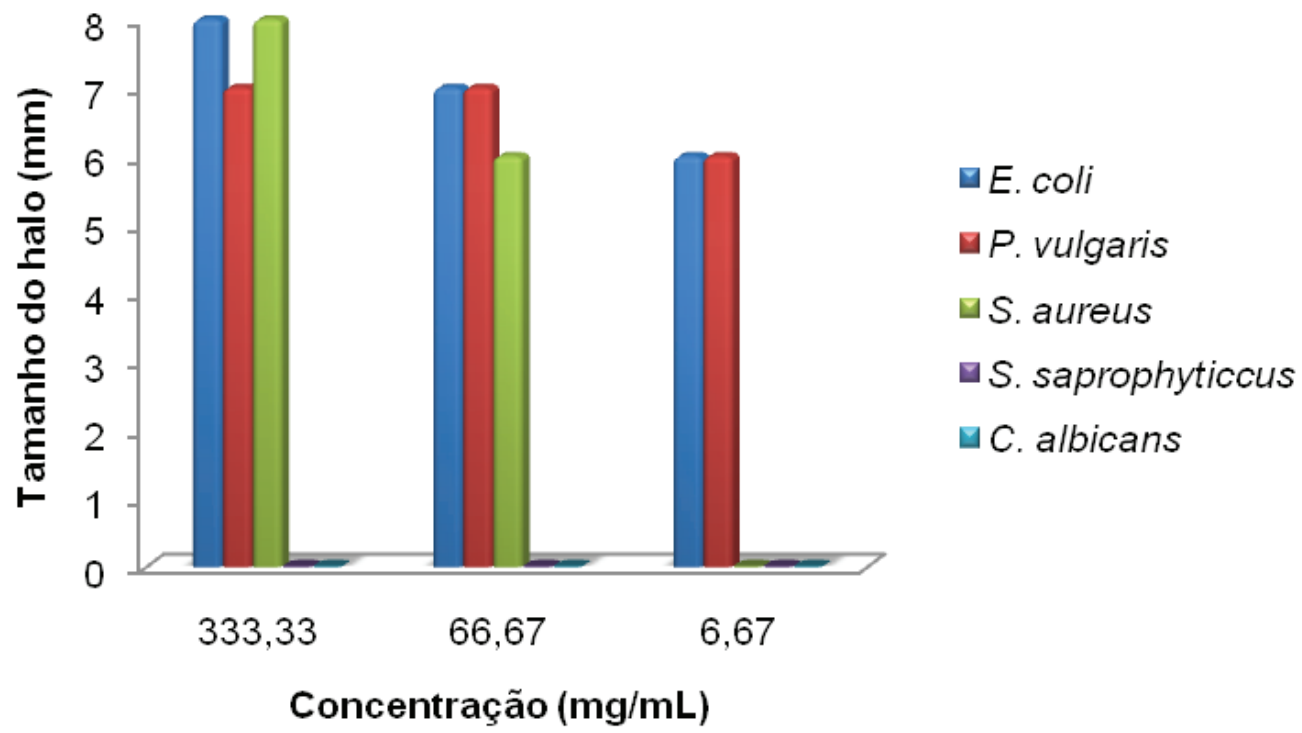

FIGURA 2. Resposta dos microrganismos frente ao extrato hidroalcoólico 40\%, - Análise por técnica de disco difusão. 
CMI de 2,0.10-3 $\mathrm{mg} / \mathrm{mL}$ (Figura 3, Tabela 2), havendo formação de halo variando entre 8 e $17,5 \mathrm{~mm}$. O extrato hidroalcoólico $40 \%$ demonstrou forte ação antimicrobiana para as enterobactérias , E. coli ; $P$. vulgaris, apresentando CMI de $6,67 \mathrm{mg} / \mathrm{mL}$ (Figura 2, Tabela 1) com valores de halos expressos em milímetros no intervalo de 6 e $8 \mathrm{~mm}$.

Avaliados pela técnica de hole-plate, os extratos alcoólico de 48 horas e 72 horas mostraramse eficientes frente ao S.aureus com CMI de 0,33 $\mathrm{mg} / \mathrm{mL}$ e 4,8.10-10 $\mathrm{mg} / \mathrm{mL}$, respectivamente (Figura 4, Tabela 4 e Figura 5, Tabela 6), com halos medidos com valores entre 10,5 a $29 \mathrm{~mm}$. Além do exposto, o extrato de 72 horas, mostrou-se eficiente frente a C. albicans com CMI de até $1,5.10^{-7} \mathrm{mg} / \mathrm{mL}$ (Figura 5, Tabela 6 ) com halo medido entre de 13 e $20 \mathrm{~mm}$. Já o extrato hidroalcoólico 40\% (Figura 6, Tabela 4), mostrou-se eficiente frente ao S.saprophyticcus com CMI de $0,33 \mathrm{mg} / \mathrm{mL}$, com halos medidos com valores entre 15 a 18,5 mm dependente da diluição. Ao avaliar os extratos alcoólicos de 48 horas e hidroalcoólico $40 \%$, pela técnica de hole-plate, nota-se formação de halos nas diluições 1:5, 1:10, $1: 20$ e 1:40, as quais representam, respectivamente, $333,33 \mathrm{mg} / \mathrm{mL}, 66,67 \mathrm{mg} / \mathrm{mL}, 6,67 \mathrm{mg} / \mathrm{mL}$ e 0,33 $\mathrm{mg} / \mathrm{mL}$. Enquanto que pela técnica de disco difusão, houve formação de halos somente até a diluição 1:20. O extrato alcoólico de 72 horas, na técnica do hole-plate, houve formação de halos em todas as diluições $(1: 5,1: 10,1: 20,1: 40,1: 80,1: 160,1: 320$ e 1:640), as quais equivalem respectivamente às seguintes concentrações, $79,19 \mathrm{mg} / \mathrm{mL}, 15,84 \mathrm{mg} /$ $\mathrm{mL}, 1,58 \mathrm{mg} / \mathrm{mL}, 7,9.10^{-2} \mathrm{mg} / \mathrm{mL}, 2,0.10^{-3} \mathrm{mg} / \mathrm{mL}$, 2,5.10-5 mg/mL, $1,5.10^{-7} \mathrm{mg} / \mathrm{mL}$ e $4,8.10^{-10} \mathrm{mg} / \mathrm{mL}$ e na técnica da disco difusão com formação de halo somente até a concentração 1:80.

\section{DISCUSSÃO}

O surgimento e disseminação de resistência microbiana tende a aumentar com o uso inadequado de antimicrobianos e dentre os microrganismos

TABELA 1. Representação do diâmetro dos halos frente ao extrato alcoólico em repouso 48 horas e extrato hidralcoólico, respectivamente, pela técnica de disco de difusão, em três concentração de extrato diferentes.

\begin{tabular}{|c|c|c|c|c|c|c|c|c|c|c|}
\hline \multirow[t]{2}{*}{$\begin{array}{l}\text { Concentra-ção } \\
\mathrm{mg} / \mathrm{mL}\end{array}$} & \multicolumn{5}{|c|}{$\begin{array}{l}\text { Tamanho do Halo em } \mathrm{mm} \text { frente ao extrato } \\
\text { alcoólico } 48 \text { horas }\end{array}$} & \multicolumn{5}{|c|}{$\begin{array}{l}\text { Tamanho do Halo em mm frente ao extrato } \\
\text { Hidralcoólico }\end{array}$} \\
\hline & E.c & P. v & S.A & S.S & C.a & E.c & P. $v$ & S.A & S.s & C.a \\
\hline 333,33 & -- & -- & $14 \mathrm{~mm}$ & $14 \mathrm{~mm}$ & -- & $8 \mathrm{~mm}$ & $7 \mathrm{~mm}$ & $8 \mathrm{~mm}$ & -- & - \\
\hline 66,67 & -- & -- & $13,5 \mathrm{~mm}$ & $12 \mathrm{~mm}$ & -- & $7 \mathrm{~mm}$ & $7 \mathrm{~mm}$ & $6 \mathrm{~mm}$ & -- & -- \\
\hline 6,67 & -- & -- & $8 \mathrm{~mm}$ & $8 \mathrm{~mm}$ & -- & $6 \mathrm{~mm}$ & $6 \mathrm{~mm}$ & -- & -- & -- \\
\hline
\end{tabular}

Legenda: E.c-Escherichia coli, P.v - Proteus vulgaris, S.a - Staphylococcus aureus, S.s - Staphylococcus sapphyticcus , C.a - Candida albicans. (--) representa que não houve formação de halo para o microrganismo correspondente.

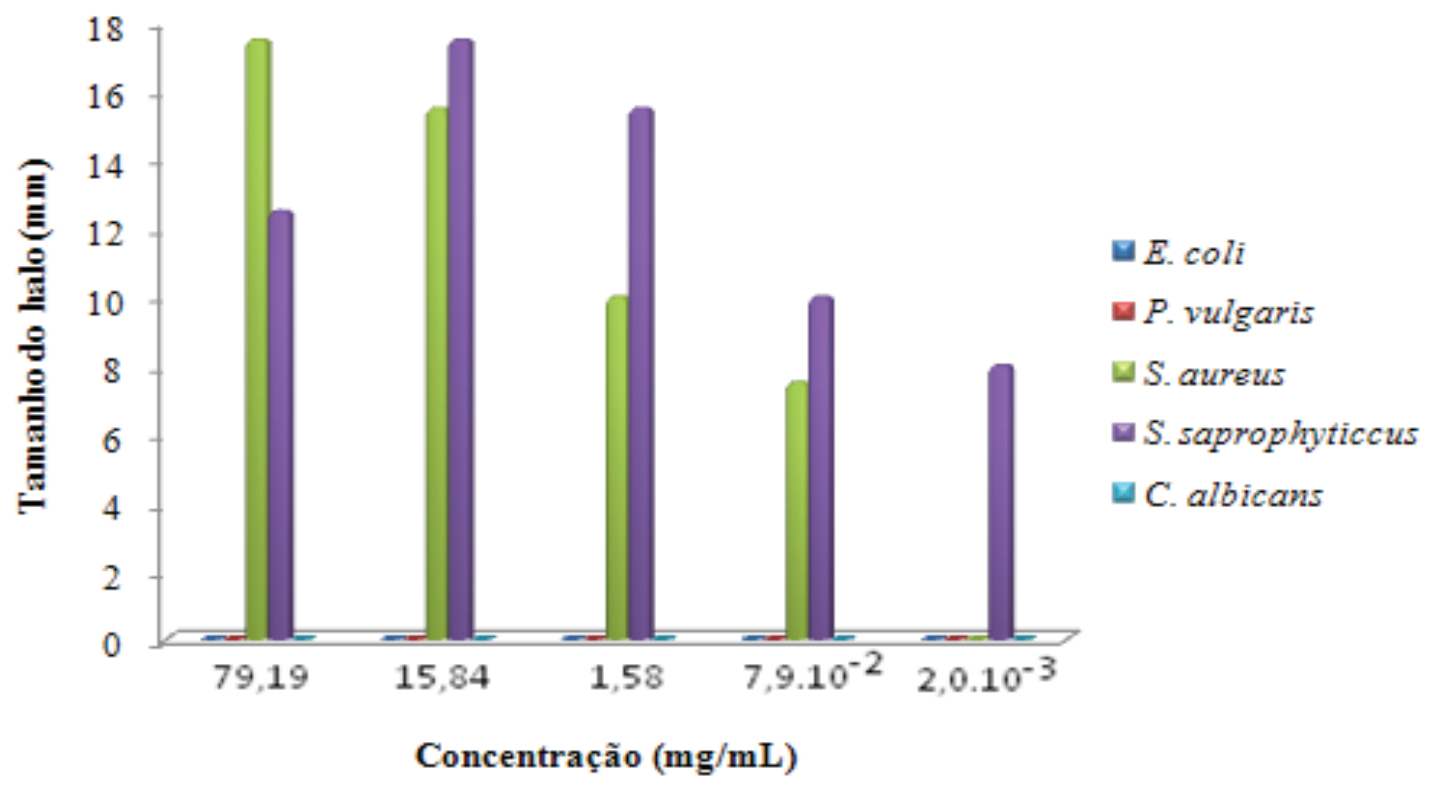

FIGURA 3. Resposta dos microrganismos frente ao extrato alcoólico (após 72 horas) - Análise por técnica de disco difusão 
TABELA 2. Representação do diâmetro dos halos frente ao extrato alcoólicopela técnica de disco de difusão em repouso 72 horas, em cinco concentrações de extrato diferentes.

\begin{tabular}{cccccc}
\hline Concentração $\mathrm{mg} / \mathrm{ml}$ & \multicolumn{5}{c}{ Tamanho do halo em mm frente ao extrato alcoólico deixado em repouso de 72 horas. } \\
\hline & E.c & P.v & S.a & S.s & C.a \\
\hline 79,19 & -- & -- & $17 \mathrm{~mm}$ & $13 \mathrm{~mm}$ & -- \\
15,84 & -- & -- & $15 \mathrm{~mm}$ & $17 \mathrm{~mm}$ & - \\
1,58 & -- & -- & $10 \mathrm{~mm}$ & $15 \mathrm{~mm}$ & - \\
$7,9.10^{-2}$ & -- & -- & $8 \mathrm{~mm}$ & $10 \mathrm{~mm}$ & - \\
$2,0.10^{-3}$ & -- & -- & -- & $9 \mathrm{~mm}$ & - \\
\hline Legenda: E.c - Escherichia coli, P.v - Proteus vulgaris, S.a - Staphylococcus aureus, S.s - Staphylococcus sapphyticcus, C.a - Candida \\
albicans. (--) representa que não houve formação de halo para o microrganismo correspondente.
\end{tabular}

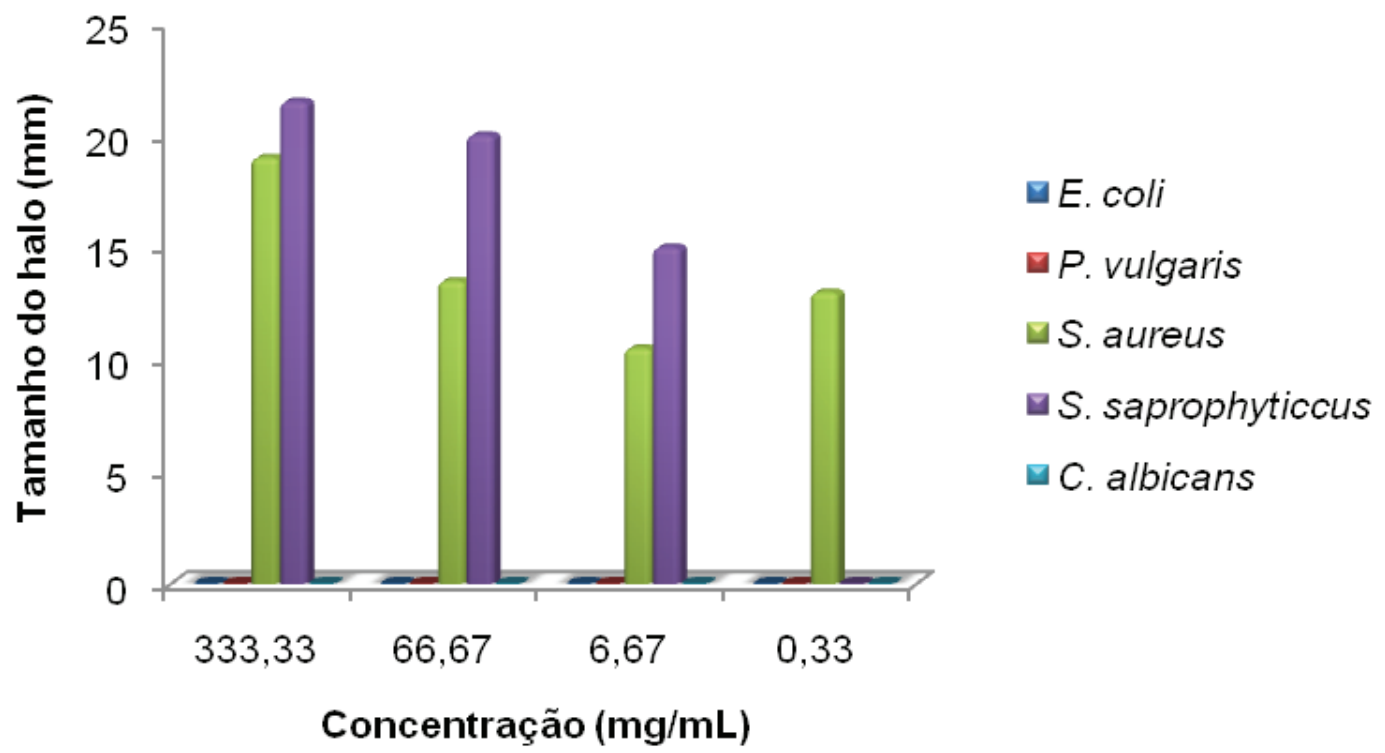

FIGURA 4. Resposta dos microrganismos frente ao extrato alcoólico (48 horas)-Análise por técnica de hole-plate.

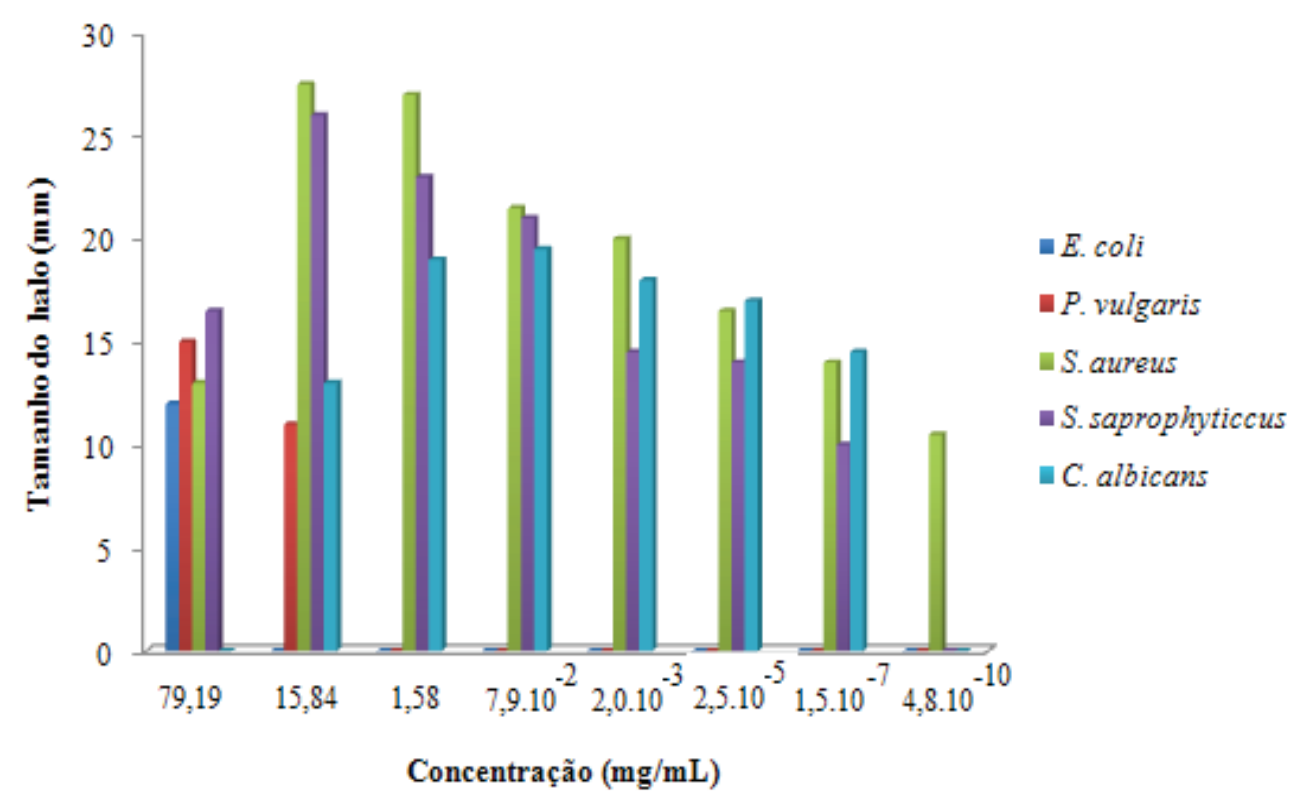

FIGURA 5. Resposta dos microrganismos frente ao extrato alcoólico (72 horas)-Análise por técnica de hole-plate. 
TABELA 3. Representação do diâmetro dos halos frente ao extrato alcoólico pela técnica do hole-plate em repouso 72 horas, em oito concentrações de extrato diferentes.

\begin{tabular}{cccccc}
\hline Concentração $\mathbf{~ m g / m l ~}$ & \multicolumn{5}{c}{ Tamanho do halo em $\mathbf{m m}$ frente ao extrato alcoólico deixado em repouso de 72} \\
horas. \\
\hline & E.c & P.v & S.a & S.s & C.a \\
\hline 79,19 & $12 \mathrm{~mm}$ & $16 \mathrm{~mm}$ & $13 \mathrm{~mm}$ & $17 \mathrm{~mm}$ & -- \\
15,84 & -- & $11 \mathrm{~mm}$ & $28 \mathrm{~mm}$ & $27 \mathrm{~mm}$ & $13 \mathrm{~mm}$ \\
1,58 & -- & -- & $27 \mathrm{~mm}$ & $23 \mathrm{~mm}$ & $19 \mathrm{~mm}$ \\
$7,9.10^{-2}$ & -- & -- & $22 \mathrm{~mm}$ & $22 \mathrm{~mm}$ & $19 \mathrm{~mm}$ \\
$2,0.10^{-3}$ & -- & -- & $20 \mathrm{~mm}$ & $14 \mathrm{~mm}$ & $18 \mathrm{~mm}$ \\
$2,5.10^{-5}$ & -- & -- & $17 \mathrm{~mm}$ & $14 \mathrm{~mm}$ & $17 \mathrm{~mm}$ \\
$1,5.10^{-7}$ & -- & -- & $14 \mathrm{~mm}$ & $10 \mathrm{~mm}$ & $15 \mathrm{~mm}$ \\
$4,8.10^{-10}$ & -- & -- & $11 \mathrm{~mm}$ & -- & --
\end{tabular}

Legenda: E.c - Escherichia coli, P.v - Proteus vulgaris, S.a - Staphylococcus aureus, S.s - Staphylococcus sapphyticcus , C.a - Candida albicans. (--) representa que não houve formação de halo para o microrganismo correspondente.

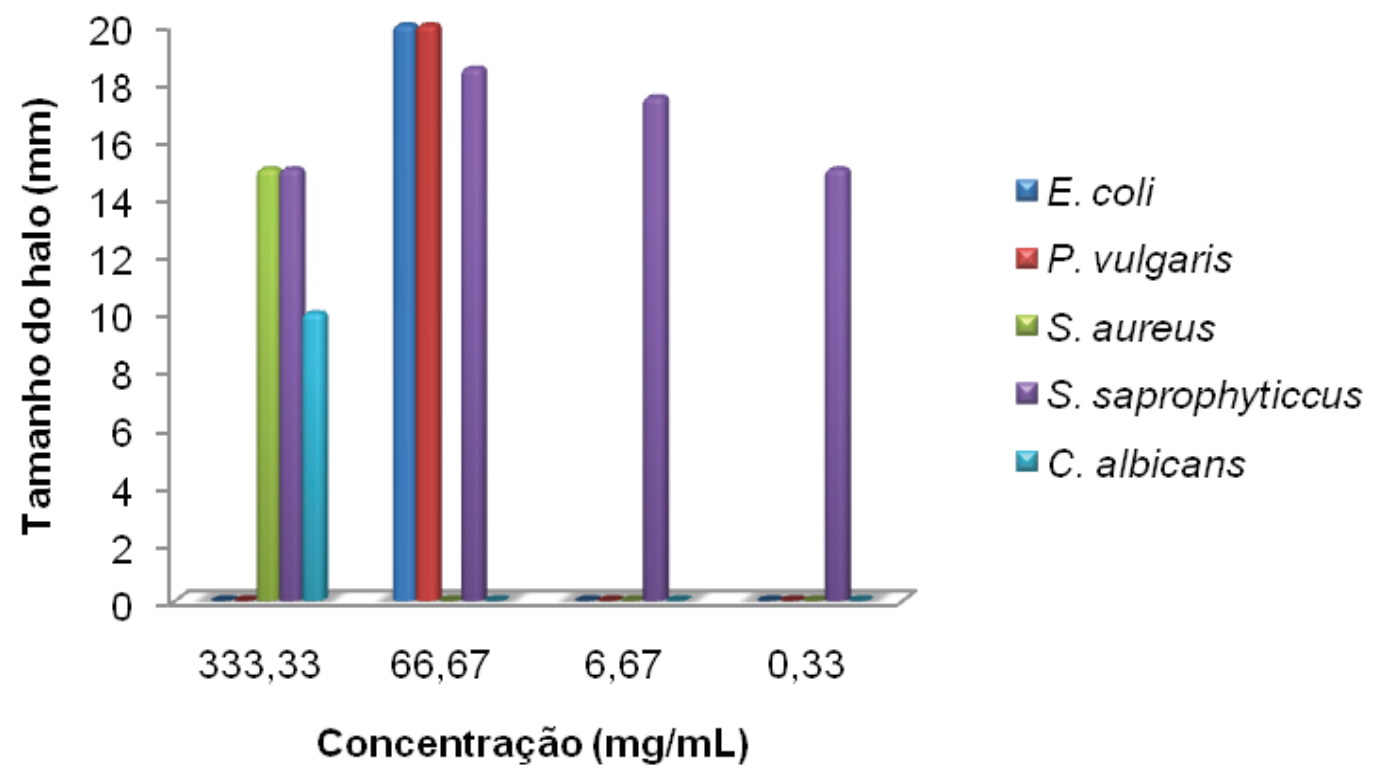

FIGURA 6. Resposta dos microrganismos frente ao extrato hidroalcoólico 40\%-

Análise por técnica de hole-plate.

TABELA 4. Representação do diâmetro dos halos frente ao extrato alcoólico 48 horas, e hidralcoólico $40 \%$, respectivamente, técnica do hole-plate, em quatro concentrações de extrato diferentes.

\begin{tabular}{|c|c|c|c|c|c|c|c|c|c|c|}
\hline \multirow[t]{2}{*}{ Concentração mg/ml } & \multicolumn{5}{|c|}{$\begin{array}{c}\text { Tamanho do halo em } \mathrm{mm} \text { frente ao extrato } \\
\text { alcoólico } 48 \text { horas. }\end{array}$} & \multicolumn{5}{|c|}{$\begin{array}{c}\text { Tamanho do halo em } \mathrm{mm} \text { frente extrato } \\
\text { hidroalcoólico } 40 \% \text {. }\end{array}$} \\
\hline & E. c & P.v & S.a & S.S & C.a & E.c & P.v & S.a & S.S & C.a \\
\hline 333,33 & -- & -- & $19 \mathrm{~mm}$ & $22 \mathrm{~mm}$ & -- & -- & -- & $15 \mathrm{~mm}$ & $15 \mathrm{~mm}$ & $10 \mathrm{~mm}$ \\
\hline 66,67 & -- & -- & $13 \mathrm{~mm}$ & $20 \mathrm{~mm}$ & -- & $20 \mathrm{~mm}$ & $20 \mathrm{~mm}$ & -- & $19 \mathrm{~mm}$ & -- \\
\hline 6,67 & -- & -- & $10,5 \mathrm{~mm}$ & $15 \mathrm{~mm}$ & -- & -- & -- & -- & $17 \mathrm{~mm}$ & -- \\
\hline 0,33 & -- & - & 13 mm & -- & -- & -- & -- & -- & $15 \mathrm{~mm}$ & -- \\
\hline
\end{tabular}

Legenda: E.c - Escherichia coli, P.v - Proteus vulgaris, S.a - Staphylococcus aureus, S.s - Staphylococcus sapphyticcus, C.a - Candida albicans. (--) representa que não houve formação de halo para o microrganismo correspondente. 
de importância epidemiológica podemos citar Staphylococcus aureus, Escherichia coli e Pseudomonas aeruginosa. Nos últimos anos, após o uso excessivo de medicamentos antimicrobianos pela população, houve um grande índice de microrganismos que se tornaram resistentes à terapia convencional. Isso fez com que a pesquisa de novas substâncias ativas para combater infecções, tanto em fontes animais como vegetais, fosse intensificada (Pereira, 2007).

Não existe um consenso sobre o nível de inibição aceitável para produtos naturais quando comparados com antibióticos padrões, tanto que alguns autores consideram somente resultados similares aos de antibióticos, enquanto outros consideram com bom potencial mesmo aqueles com níveis de inibições superiores. Aligianis et al. (2001) propuseram uma classificação para materiais vegetais com base nos resultados de MIC, considerando como: forte inibição - MIC até $500 \mu \mathrm{g} /$ $\mathrm{mL}$; inibição moderada - MIC entre 600 e $1500 \mu \mathrm{g} / \mathrm{mL}$ e como fraca inibição - MIC acima de $1600 \mu \mathrm{g} / \mathrm{mL}$.

Estudos como os de Komuraiah et al. (2009) e Silva et al. (2010), referenciam que o S. aureus, quando sensível, apresenta halo que variaram entre 3 e $16 \mathrm{~mm}$, resultados este bastante semelhantes com os resultados expressos neste estudo, que chegam a inclusive superar os valores máximos obtidos nos estudos referenciados com valores medidos entre 8 e $29 \mathrm{~mm}$.

Silva et al. (2010), citam que não observaram resultados em relação a $E$. coli e $C$. albicans com formação de halo, porém este estudo demonstrou que a Phyllanthus sp obteve ação antimicrobiana frente os microrganismos testados com valor de CMI de $16 \mathrm{mg} / \mathrm{mL}$ e $0,70 \mathrm{mg} / \mathrm{mL}$. No presente estudo observou-se ação antimicrobiana para ambos os microrganismos referenciados acima, a E. coli com valor de CMI 6,67 mg/mL e a C. albicans com valor de CMI 4,8.10-10 $\mathrm{mg} / \mathrm{mL}$, pela técnica de disco difusão a E. coli, mostrou-se sensível com halos de inibição variando entre 6 e $8 \mathrm{~mm}$ e para $C$. albicans entre 13 e $19,5 \mathrm{~mm}$, dependente da diluição.

Nos estudos realizados por Barbosa et al. (2009), foi demonstrado que os extratos alcoólicos a $10 \%$ e $20 \%$, não apresentaram atividade antimicrobiana, enquanto que os extratos alcoólicos de $30 \%$ a $50 \%$ demonstraram pequena atividade antimicrobiana e os extratos de $60 \%$ a $80 \%$ promoveram uma grande inibição do crescimento microbiano. A atividade antimicrobiana ocorre porque os flavonóides não são solúveis em água, por se tratar de um solvente de alta polaridade. $O$ trabalho desenvolvido demonstrou resultados semelhantes, uma vez que as infusões não inibiram o crescimento antimicrobiano, o extrato hidroalcoólico $40 \%$ pouco inibiu o crescimento e os extratos alcoólicos em maiores concentrações inibiram o crescimento antimicrobiano.

Baratelli et al. (2001) demonstraram que extratos de $P$. niruri foram ativos frente a 26 cepas de Staphylococcus aureus, incluindo aquelas sensíveis e resistentes à meticilina, podendo representar uma nova opção na terapêutica de infecções estafilocócicas.

Oliveira et al. (2007) ao realizarem um rastreamento com 26 plantas do sudeste brasileiro, verificaram que os melhores resultados foram obtidos com as plantas Lantana lilacina e Phyllanthus tenellus, uma vez que estas apresentaram boa atividade bactericida após passarem por um processo de microdiluição.

No presente estudo foi observado, portanto, maior eficiência dos extratos alcoólicos em relação às infusões e que a técnica de hole-plate mostrouse mais eficiente em relação à técnica de disco difusão. Os cocos Gram positivos foram os mais susceptíveis frente aos extratos utilizados. O gênero Staphylococcus apresentou maior sensibilidade quando comparado aos bacilos Gram negativos e leveduras. Conforme Sartori (2005) a parede celular bacteriana dos Gram positivos é menos complexa e apresenta maior permeabilidade quando comparada as Gram negativas. Tal resultado pode ser explicado porque a membrana externa das bactérias Gram negativas apresenta-se como uma barreira a penetração de numerosas moléculas de antibióticos, e, além disso, o espaço periplasmático contém enzimas capazes de quebrar moléculas estranhas (Tortora et al., 2005).

\section{REFERÊNCIAS}

AITA, A.M. et al. Espécies medicinais comercializadas como "quebra-pedras" em Porto Alegre, Rio Grande do Sul, Brasil. Revista Brasileira de Farmacognosia, v. 19 (2A): 471-477, 2009.

ALIGIANIS N. et al. Composition and antimicrobial activity of the essential oil of two Origanum species, Journal agricultural and food chemistry. V.49: 4168-4170, 2001.

ALMEIDA, M. C. et al. Ocorrência de infecção urinária em pacientes de um hospital universitário. Revista de Ciências Farmacêuticas Básica e Aplicada, v. 28, n.2, p. 215- 219, 2007.

BARATELLI, T.G. et al. Avaliação do potencial antimicrobiano dos extratos hexânico e acetato de etila de Phyllanthus tenellus e hexânico Phyllanthus niruri frente a bactérias hospitalares. V Jornada Paulista de Plantas Medicinais, Anais do Congresso, v. 1. p.161-161, 2001.

BARBOSA, M.H. et al. Ação terapêutica da própolis em lesões cutâneas. Acta Paulista de Enfermagem, v. 22 (3): 318-22. 2009.

Rev. Bras. PI. Med., Campinas, v.17, n.3, p.427-435, 2015. 
BRASIL. A fitoterapia no sUS e o programa de pesquisas de plantas medicinais da Central de Medicamentos. Ministério da Saúde, Brasília, 2006. 148p.- (Série B. Textos Básicos de Saúde).

CASTRO-CHAVES, C. et al. O Phyllanthus niruri L. induz caliurese dissociada da diurese e da natriurese em ratos acordados. Revista Brasileira de Farmacognosia, v. 12, suppl.1, pp. 2-4, 2002.

DUARTE, M.C.T. Atividade Antimicrobiana de Plantas Medicinais e Aromáticas Utilizadas no Brasil . Multiciência, Construindo a História dos Produtos Naturais p.7, 2006.

FERNANDES, T.T. et al. Atividade Antimicrobiana das Plantas Plathymeniareticulata, Hymeneacourbaril e Guazumaulmifolia. Revista de Patologia Tropical, v. 34, n.2, p. 113-122, 2005.

GARCIA, C.M. et al. Estudo Morfo-Anatômico de Phyllanthus niruru I. e Phyllanthus tenellus Roxb. Acta Farmaucêutica Bonaerense, v. 23, n. 1, 67-70, 2004.

HEILBERG, I. P.; SCHOR, N. Abordagem Diagnóstica e Terapêutica na Infecção do Trato Urinário - ITU. Revista da Associação Médica Brasileira, v. 49 (1): 109-16, 2003

HORNER, R. et al. Prevalência de microrganismos em infecções do trato urinário de pacientes atendidos no Hospital Universitário de Santa Maria. Revista da Sociedade Brasileira de Análises Clínicas, v. 38, n. 38, n. 3: 147-150, 2006.

JANSEN, A.M. et al. Antimicrobial activity of essential oils from Greek Sideritis species. Pharmazie, v. 45, n.1, p.70-71, 1987.

KOMURAIAH, A. et al. Antibacterial studies and phytochemical constituents of South Indian Phyllanthus species. African Journal of Biotechnology, v. 8 (19), pp. 4991-4995, 2009.

KONEMAN, E.W. et al. Diagnóstico Microbiológico - Texto e Atlas Colorido. $5^{\text {a }}$ ed., Rio de Janeiro: Editora Médica e Científica, 2001.1365p.

LUCCHETTI, G. et al. Infecção do trato urinário: análise da freqüência e do perfil de sensibilidade dos agentes causadores de infecção do trato urinário em pacientes com cateterização vesical crônica. Jornal Brasileiro de Patologia e Medicina Laboratorial, v.41, n. 6, p. 383-9, 2005.
NASCIMENTO, V.T. et al. Controle de qualidade de produtos à base de plantas medicinais comercializados na cidade do Recife - PE: erva-doce (Pimpinella anisum L.), quebra-pedra (Phillanthus ssp), espinheira santa (Maytenus ilicifilia Mart) e camomila (Matricaria recutita L.). Revista Brasileira de Plantas Medicinais. v. 7, n.3, p56-64, 2005.

OLIVEIRA, D.F. et al. Antibacterial activity of plant extracts from Brazilian southeast region. Fitoterapia, v. 78, p. $142-145,2007$

PACKER, J.K.; LUZ, M.M.S. Métodos para avaliação e pesquisa da atividade antimicrobiana de produtos de origem natural. Revista Brasileira de Farmacognosia, v. 17, p. 102-107, 2007.

PEREIRA, R.S. et al. Atividade antibacteriana de óleos essenciais em cepas isoladas de infecção urinária. Revista Saúde Pública, v. 38 (2):326-8, 2004.

PEREIRA, J.F.S. Avaliação do potencial antimicrobiano do extrato da casca de Schinopsis brasiliensis Engler: um estudo baseado na indicação etnofarmacológica. 2007, 60p. Monografia de Graduação em Ciências Biológicas - Departamento de Biologia, Universidade Estadual da Paraíba, Campina Grande-PB.

RITTER, M.R. et al. Plantas usadas como medicinais no município de Ipê, RS, Brasil. Revista Brasileira de Farmacognosia, v.12, n. 2, p. 51-62. jul-dez 2002.

SARTORI, M.R.K. Atividade antimicrobiana de fração de compostos puros obtidos das flores da Acmela brasiliensis Spreng (Wedelia paludosa) (Asteraceae). 2005, Dissertação (Mestrado) Ciências Farmacêuticas. Universidade do Vale do Itajai, Santa Catarina.

SCHAECHTER, M. et al. Microbiologia. $3^{a}$ ed. Rio de Janeiro: Ed. Guanabara Koogan, 2002. 642p.

SILVA, T.C.L. et al. Atividade antimicrobiana de três espécies de Phyllanthus (quebra-pedra) e de seu produto comercial. Revista de Enfermagem. v. 4(1):88-92, 2010.

TORTORA, G.J.; FUNKE, B.R.; CASE, C.L. Microbiologia. $8^{a}$ ed. Porto Alegre: Ed. Artmed, 2005. 894p.

VIEIRA NETO, O.M. Infecção do trato urinário. Medicina, v.36: 365-369. 2003. 